\title{
Cannabis medicinal: ¿se asoma una nueva luz para los pacientes con trastornos psiquiátricos?
}

\author{
Medicinal cannabis: is a new light showing for patients with psychiatric disorders? \\ Vianka Cevallos-Zelada ${ }^{1, a}$
}

\section{Sres. Editores:}

Los problemas de salud mental representan un reto importante para la salud pública mundial y corresponden a una de las principales cargas de morbilidad (1). Alrededor del mundo, se han venido desarrollando estudios que buscan evidencia del uso de cannabis medicinal como una terapia alternativa para tratar a pacientes con diferentes trastornos psiquiátricos lo cual podría ampliar sus opciones de tratamiento, siendo de gran importancia en la situación en la que nos encontramos donde las emociones y los pensamientos negativos se extienden amenazando la salud mental de la población.

En un estudio epidemiológico de Inglaterra sugieren que el cannabidiol (CBD), componente del cannabis medicinal, tiene la capacidad de reducir los síntomas psicóticos, de ansiedad y de abstinencia mediante varias propiedades farmacológicas hipotetizadas como que puede ejercer efectos antipsicóticos en la esquizofrenia principalmente a través de la facilitación de la señalización endocannabinoide y el antagonismo del receptor cannabinoide tipo 1 (2), o que puede exhibir efectos ansiolíticos agudos en pacientes con trastorno de ansiedad social generalizada a través de la modificación del flujo sanguíneo cerebral en sitios específicos del cerebro y agonismo del receptor de serotonina 1A (2). En otro estudio, el efecto ansiolítico del CBD se sustenta en la activación del receptor de serotonina 5HT1A y el bloqueo de la recaptación de la araquidonoiletanolamina (AEA), con aumento en los niveles de este cannabinoide endógeno, disminuido por la respuesta al estrés. En pacientes con trastorno de ansiedad social, el CBD reduce la ansiedad inducida por la exposición simulada a un evento social aversivo (3). También, en un estudio de EEUU se demostró que existe una recomendación de grado B que respalda el uso de CBD para el tratamiento de la esquizofrenia, el trastorno de ansiedad social, el trastorno del espectro autista (TEA) y el trastorno por déficit de atención con hiperactividad (TDAH). Sin embargo, hay pruebas más débiles de su utilidad para el insomnio, ansiedad, trastorno bipolar, trastorno de estrés postraumático y síndrome de Tourette (4). Pero a pesar de estos beneficios, así como es importante la investigación preclínica que sugiere su efecto modulador sobre numerosos síntomas neurológicos, emocionales y psiquiátricos, la evidencia que respalda el consumo de cannabis en estos casos, es aún insuficiente y actualmente faltan ensayos controlados aleatorios bien diseñados para considerarlo como una opción de tratamiento dado que existe evidencia débil de los resultados beneficiosos de los cannabinoides en la ansiedad, el estado de ánimo y los trastornos del sueño (5) obteniendo como conclusión la importancia de ahondar en este tema que de ser comprobado como beneficioso para los pacientes dado su posible uso como tratamiento terapéutico coadyuvante o a trastornos refractarios a las terapias convencionales, ayudaría a muchos pacientes.

\section{Correspondencia}

Vianka Cevallos-Zelada

Av. Benavides 5440, Santiago de Surco, Lima 33 Perú

Teléfono: 961719699

Correo electrónico: vianka95vet@gmail.com

Facultad de Medicina Humana, Universidad Ricardo Palma. Lima, Perú.

a Estudiante de Medicina Humana. ORCID ID: 0000-0001-9171-4700 


\section{REFERENCIAS BIBLIOGRÁFICAS}

1. Huarcaya-Victoria J. Consideraciones sobre la salud mental en la pandemia de COVID-19. Rev Peru Med Exp Salud Publica. 2020; 37(2): 327-334. DOI: 10.17843/rpmesp.2020.372.5419

2. Khan R, Naveed S, Mian N, Fida A, Raafey MA, Aedma KK. The therapeutic role of Cannabidiol in mental health: a systematic review. J Cannabis Res. 2020;2(1):2. doi: 10.1186/s42238-019-0012-y

3. Mandolini GM, Lazzaretti M, Pigoni A, Oldani L, Delvecchio G, Brambilla P. Pharmacological properties of cannabidiol in the treatment of psychiatric disorders: a critical overview. Epidemiol Psychiatr Sci. 2018;27(4):327-335. doi: 10.1017/ S2045796018000239

4. Muñoz JF. El cannabidiol y sus indicaciones en psiquiatría. Medicina UPB. 2021; 40(1): 65-76. DOI: 10.18566/medupb.v40n1.a09

5. Graczyk M, Lukowicz M, Dzierzanowski $T$. Prospects for the use of cannabinoids in psychiatric disorders. Front Psychiatry. 2021; 12: 276.

Recibido: 11/05/2021

Aceptado: 01/07/2021 